Criação / Escultura 


\title{
Amilcar de Castro, escultura também é cosa mentale
}

\author{
JOÃO GUIMARÃES VIEIRA
}

$\mathrm{C}$

ARLOS DRUMOND DE ANDRADE, mineiro de Itabira toda de ferro, onde as ferraduras batem como sinos nas calçadas com noventa por cento de ferro, achava que os itabiranos carregavam igualmente oitenta por cento de ferro nas almas.

Por isso sou triste, orgulhoso: de ferro.

Amilcar de Castro, também mineiro, mas não de zona de mineração, pois nasceu em Paraisópolis, no sul de Minas (1), não parece ser interiormente de ferro como o poeta - que, de resto, não tinha tanto ferro na alma, como pensava.

Mas, se não é, como o itabirano, de ferro por dentro, nem por isso deixou de dialogar muito cedo com esse material, numa aproximação que não se fez, certamente, pelo que ele oferece de decorativo e de atraente, pois não é decorativo nem atraente.

Trata-se, pelo contrário, de material que os primeiros a usá-lo, nas construções no final do século XVIII e na primeira metade do XIX, tiveram vergonha de exibi-lo, escondendo-o na alvenaria.

Amilcar de Castro, porém, começou a usar o ferro desde as primeiras obras e parece não ter sentido, no decorrer do tempo, a tentação de substituí-lo por outro material mais nobre e mais agradável.

Em sua obra escultórica, a participação do ferro não é, por isso, de apenas noventa por cento como nas calçadas de Itabira, mas de cem por cento - ou quase.

Essa opção é significativa. Adotando-o, o escultor renuncia ao gosto de seduzir o espectador com o que não integra a estrita organização formal que impõe à sua obra.

Não sendo decorativo nem charmoso, o ferro confere, todavia, às esculturas de Amilcar de Castro, uma severa dignidade, mesmo àquelas que, por exigência de mercado, são realizadas em pequenas dimensões, para ornamentar interiores. 
É, no entanto, em escala monumental que elas ganham a serena grandeza de que falava Winckelmann referindo-se à arte grega.

Mas o seu caráter monumental não se expressa apenas no tamanho e sim, ou principalmente, na consciência formal que orienta $o$ seu trabalho como escultor.

Inimigo da eloqüência, do ornato, da gesticulação abusiva, alcança a monumentalidade pela forma despojada, de natureza fundamentalmente antibarroca.

Assim, à serena grandeza devemos associar a nobre simplicidade para alcançar a fórmula com que o citado historiador alemão definia o classicismo grego.

Seria abusivo dizer que Amilcar de Castro é um clássico? Não creio, desde que a essência do clássico, sua natureza definidora, seja examinada fora do plano temporal e histórico, como uma constante da história da arte, desde a antigüidade aos tempos modernos.

Uma de suas características, talvez a mais importante, está na conhecida lei da economia de meios. Em literatura, é clássico, por exemplo, o conceito de que escrever é cortar palavras, ou como disse há meio século atrás o humorista Bastos Tigre, numa crônica no extinto Correio da Manbã: dificil é escrever fácil.

Outra postura clássica, ainda no campo literário, está no poema Procura da Poesia, de Carlos Drumond de Andrade: Não faças versos sobre acontecimentos, diz o poeta, para aconselhar em seguida:

\section{Penetra surdamente no reino das palavras,}

Lá estão os poemas que esperam ser escritos.

Concentrar-se na palavra corresponde, na pintura, concentrar-se nas linhas e nas cores, como fez Cézanne (dizia mais ou menos que o que lhe interessava na pintura era a pintura) ou como escreveu certa vez Georges Braque: J'aime la règle qui corrige l'émotion. J'aime l'émotion qui corrige la règle.

Outro pensamento deste mesmo pintor merece ser citado: Oublions les choses, ne considérons que les rapports.

A opção pelo essencial, a consciência de que na obra de arte interessa mais o problema das relações do que as coisas, tudo isto é inegavelmente de natureza clássica e tudo isto está ligado à obra de Amilcar de Castro.

O correspondente ao conselho para não fazer versos sobre acontecimentos vem sendo seguido pelo escultor com rara lucidez desde os anos 50, 
quando participou dos movimentos de renovação artística ocorridos em São Paulo e no Rio.

Na mesma postura do poeta com as palavras, Amilcar de Castro também não faz esculturas sobre isto ou sobre aquilo, nunca pretendeu com elas registrar acontecimentos épicos, sociais ou sentimentais, nem retratar amigos ou a si próprio.

Sua escultura celebra apenas a conquista do espaço tridimensional, é construção que se justifica por si mesma, forma cuja razão de ser é a própria forma e que concentra seu significado nas precisas relações estabelecidas pelo escultor.

As mil faces secretas sob a face neutra, que Drumond anuncia ou denuncia nas palavras, Amilcar de Castro descobre em formas geométricas simples - no triângulo ou no retângulo, no círculo ou no quadrado - através da sensível comprovação de que basta cortá-las, dobrá-las e juntá-las em novas e múltiplas relações para atingir a face ainda não revelada da beleza.

Nada mais simples, portanto, do que o seu processo criador. Do desenho no papel ao corte e à dobra das pesadas chapas de ferro, chega à escultura orientado por uma precisa geometria, sensível e sem o mínimo apelo à retórica.

Nada é supérfluo em sua escultura. Nem mesmo a ferrugem que, com o tempo, ocupa a superficie lisa das chapas de ferro.

Dizem que Amilcar de Castro aceita-a de bom grado, pois confere autenticidade ao material, que não é para ele mero suporte, mas é a própria escultura como foi concebida.

Na memorável retrospectiva de Amilcar de Castro no Paço Imperial do Rio de Janeiro, realizada em junho de 1989 (2), presenciei o trabalho para a instalação, na praça 15 de Novembro, ao lado do edificio, de uma das quatro esculturas que não puderam ser montadas no interior, devido às suas proporções e peso.

Enquanto acompanhava o lento e penoso trabalho dos operários, pensei na distinção que Leonardo da Vinci fazia entre pintura e escultura, ambas integrando, ainda no seu tempo, as artes consideradas servis, isto é, de escravos, inferiorizadas socialmente em relação às artes liberais, como a poesia, cultivadas pelos homens livres.

Como essa classificação era feita para distinguir as artes manuais das artes elaboradas pela mente, Leonardo da Vinci alegava que o uso do pincel pelo pintor era comparável ao uso da pena pelo poeta, sendo mero instrumento para uma criação cuja essência era, como a poesia, puramente espiritual.

Mas, se a pintura, que Leonardo considerava inclusive superior à poesia, era cosa mentale e deveria ser aceita como tal, o mesmo não ocorria com a escultura, 
cujo esforço físico por parte do escultor atrelava-a aos trabalhos manuais e conseqüentemente às artes servis.

Podemos supor que, assim, Leonardo da Vinci excluía de sua reivindicação o seu desafeto Miguel Ângelo, que vivia em permanente luta corporal com pesados blocos de mármore, extraídos sob sua orientação das pedreiras de Carrara.

O caso de Amilcar de Castro é um pouco diferente. Não é ele quem corta e dobra as pesadas chapas de ferro, mas sua tarefa é de apenas supervisionar a feitura da obra, a cargo de operários especializados.

Ainda assim cabe indagar se a poesia, que anima e zela pela perenidade da obra de arte, habita apenas as obras materialmente frágeis - um desenho de Klee ou de Guignard - ou pode aninhar-se igualmente em gigantescas e pesadíssimas estruturas de ferro, cobertas às vezes de ferrugem, como as que nascem visualizadas por Amilcar de Castro a partir de desenhos geométricos feitos e recortados de folhas de papel.

Em depoimentos feitos em diferen-

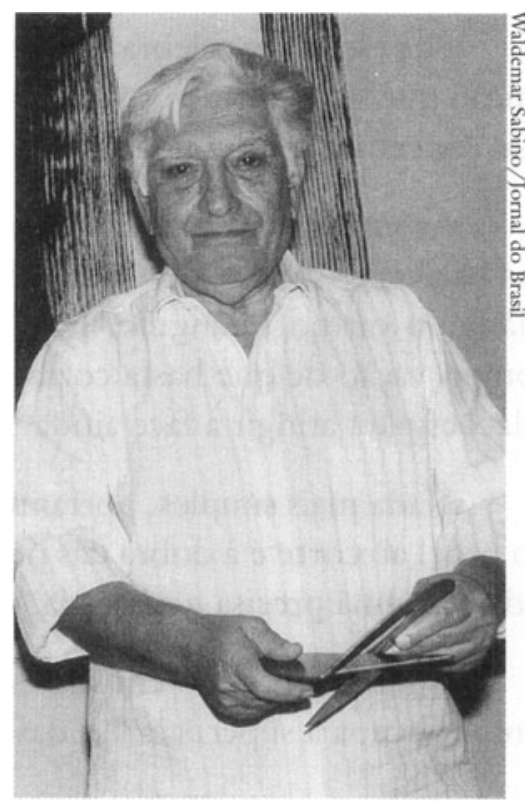

Amilcar de Castro tes épocas, Amilcar de Castro gosta de usar a expressão pensar o espaço para referir-se à sua atividade como escultor. A escultura, por conseguinte, tanto quanto a pintura, também é cosa mentale.

E, no seu caso, como a apreensão do espaço é feita sem o apoio de episódios ou acontecimentos à maneira da escultura tradicional, mas apenas com formas indevidamente chamadas de abstratas, a coisa mental de Leonardo da Vinci aparece em sua obra com inquestionável pureza, como aguda reflexão sobre as mil faces secretas da forma - da forma em si e não da forma de coisas existentes, como na escultura figurativa.

Ao contrário de tantos outros artistas, escultores ou pintores, que procuram renovar-se experimentando novas técnicas e novos materiais, ou adaptando sua atividade aos novos conceitos que se sucedem, atropelando-se, no plano teórico da criação artística, Amilcar de Castro constrói sua obra absolutamente fiel às suas convicções de quase meio século, obediente às exigências do material que utiliza e às suas intuições mais profundas.

Com isso, responde por uma obra que o coloca, sem favor, entre os mais importante escultores contemporâneos. 
Entre os mais ou o mais, se considerarmos a singular coerência e excepcional vigor de sua obra, levada a efeito sem concessões, a não ser ao espírito criador.

\section{Notas}

1 Amilcar de Castro nasceu no dia 8 de julho de 1920. Passou a infância em várias cidades do sul de Minas, transferindo-se na adolescência para Belo Horizonte, onde freqüentou o curso de Guignard e recebeu aulas de escultura com Frans Weissmann. No Rio, em 1953, trabalhou como paginador na revista Manchete e no Jornal do Brasil, no qual realizou importante renovação gráfica, considerada um marco na imprensa brasileira. Prêmio de Viagem do Salão Nacional de 1967 e bolsista da Fundação Guggenheim, passou três anos nos Estados Unidos. De volta ao Brasil, fixou-se de novo em Belo Horizonte.

2 A novidade, pelo menos para os cariocas, apresentada na retrospectiva do Paço Imperial, foram as pinturas, que o autor e a crítica preferem chamar de desenhos, exibidas juntamente com as esculturas. Nesses trabalhos, cor e textura da trincha no suporte contrastam com as esculturas de ferro, mas nem por isso rompem com a unidade e a cocrência que caracterizam a obra de Amilcar de Castro.

Joño Guimarães Vieira é professor de História da Arte. 


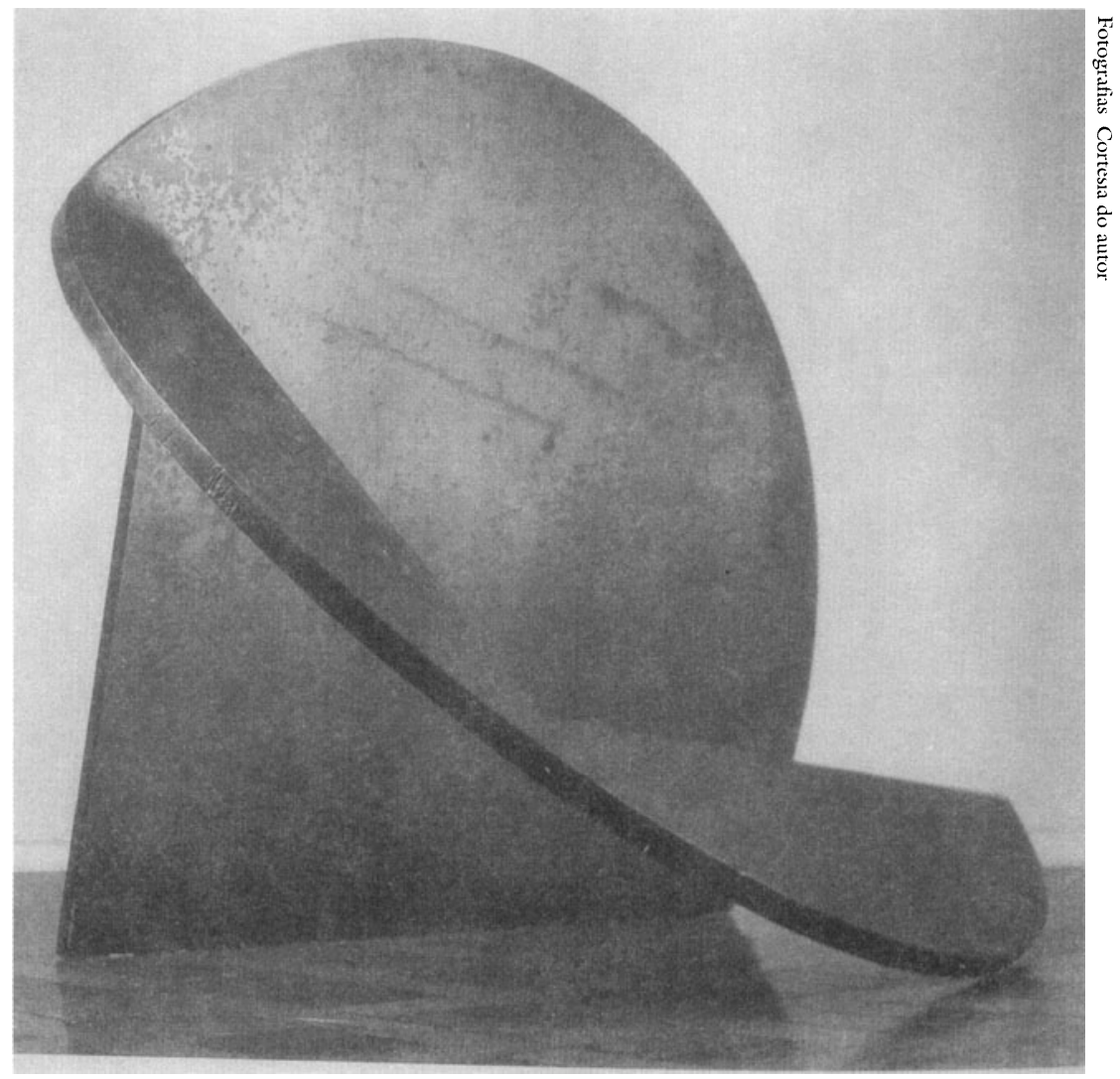

S/título, 1967. Ferro. Col. Museu Nacional de Belas Artes. 


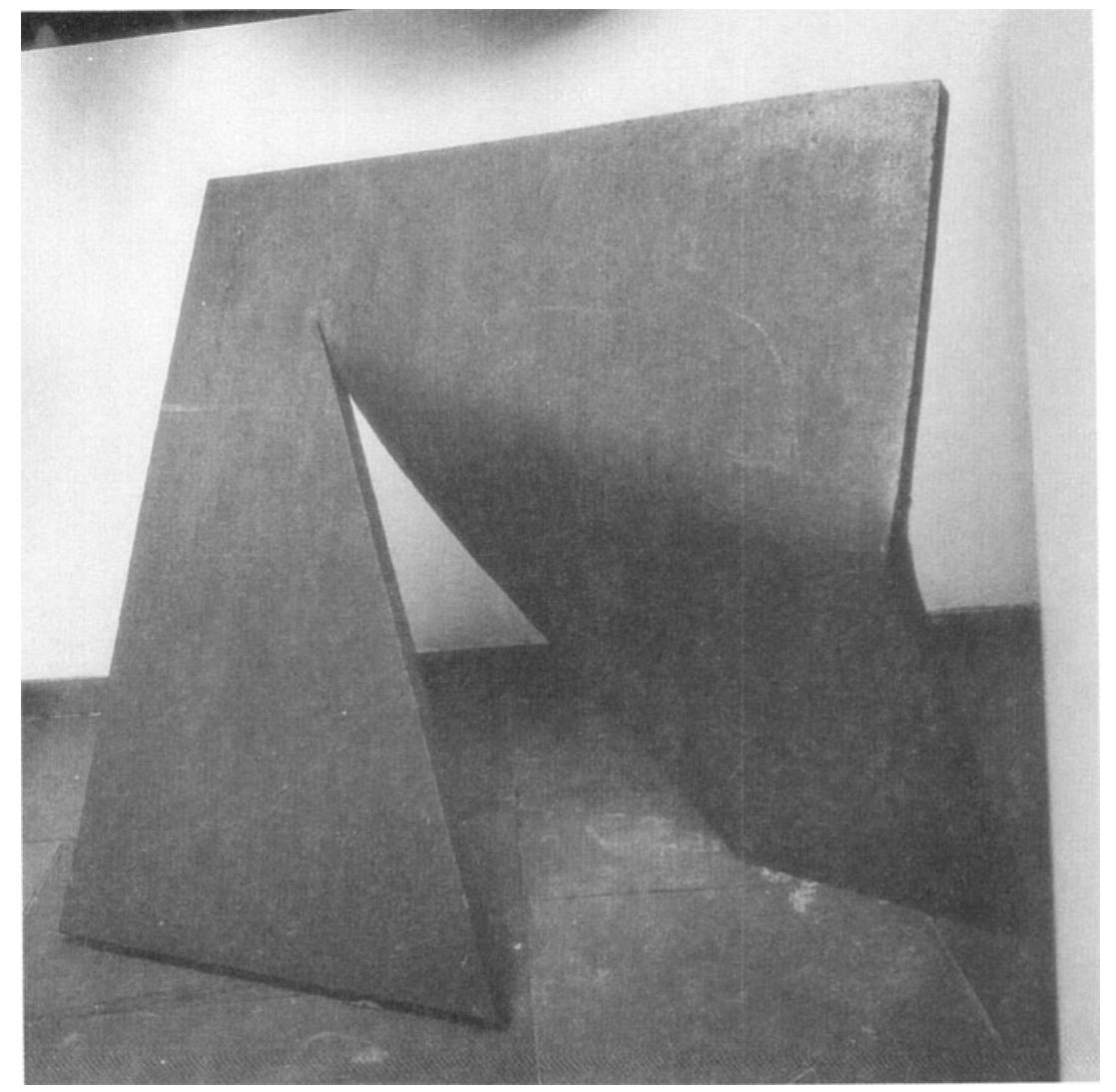

S/título, s/d. Ferro. Col. Raquel Arnaud. 


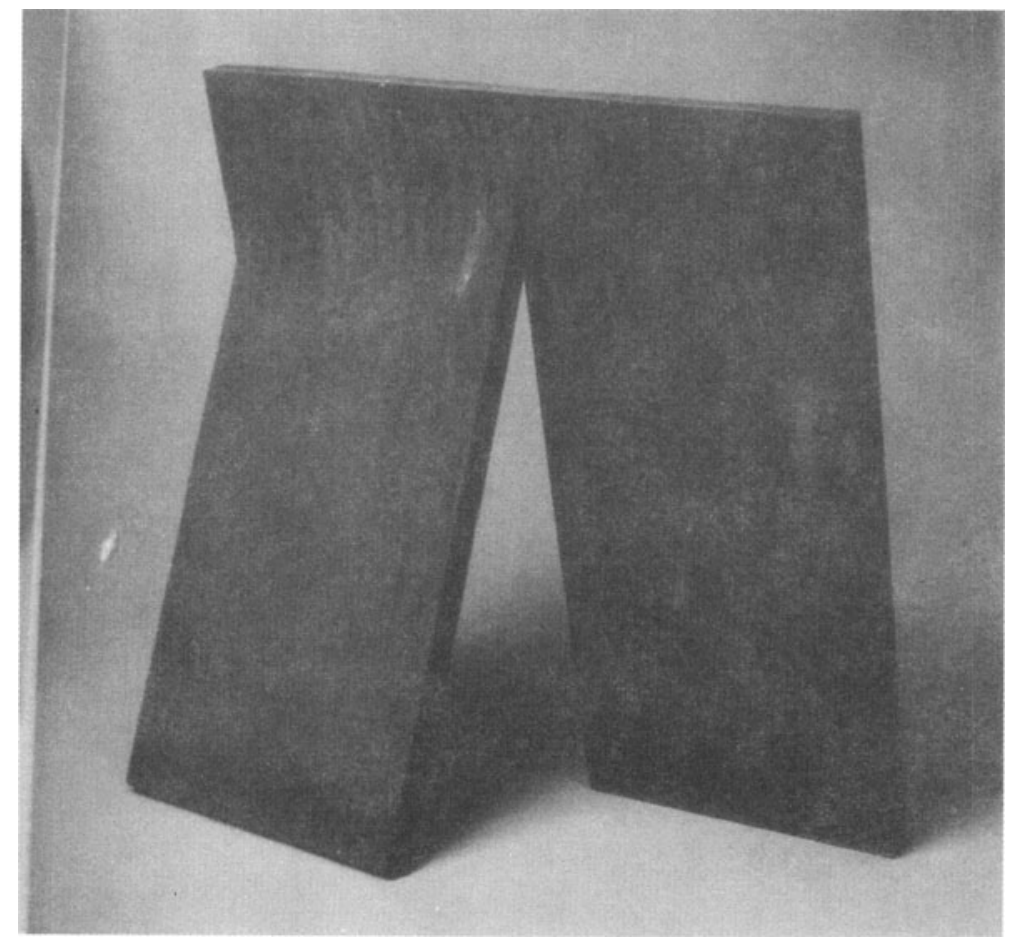

S/título, s/d. Ferro. Col. Carlos Vergara. 


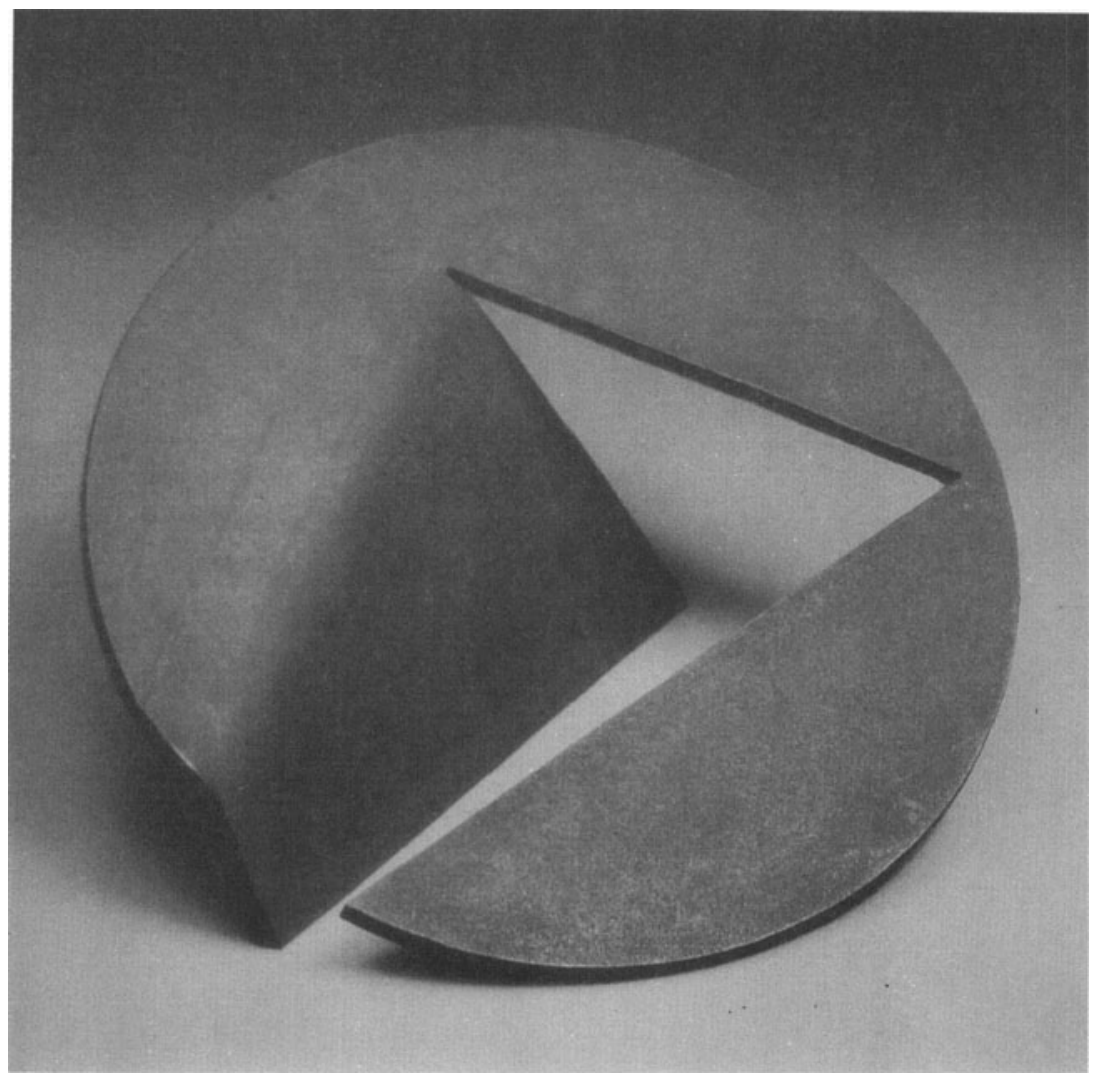

S/título, s/d. Ferro. Col. particular. 